\title{
Gamma Knife radiosurgery for posterior fossa meningiomas: a multicenter study
}

\author{
Jason P. Sheehan, MD, PhD, ${ }^{1}$ Robert M. Starke, MD, ${ }^{1}$ Hideyuki Kano, MD, PhD, ${ }^{2}$ \\ Gene H. Barnett, MD, MBA, ${ }^{5}$ David Mathieu, MD, ${ }^{4}$ Veronica Chiang, MD, ${ }^{6}$ James B. Yu, MD, ${ }^{6}$ \\ Judith Hess, BA, ${ }^{6}$ Heyoung L. McBride, MD, ${ }^{7}$ Norissa Honea, PhD, ${ }^{7}$ Peter Nakaji, MD, ${ }^{7}$ \\ John Y. K. Lee, MD, ${ }^{3}$ Gazanfar Rahmathulla, MD, ${ }^{5}$ Wendi A. Evanoff, BA, ${ }^{5}$ \\ Michelle Alonso-Basanta, MD, PhD, ${ }^{3}$ and L. Dade Lunsford, MD ${ }^{2}$
}

1 University of Virginia, Charlottesville, Virginia; ${ }^{2}$ University of Pittsburgh, Pennsylvania; ${ }^{3}$ University of Pennsylvania, Philadelphia, Pennsylvania; ${ }^{4}$ University of Sherbrooke, Quebec, Canada; ${ }^{5}$ Cleveland Clinic, Cleveland, Ohio; ${ }^{6}$ Yale University, New Haven, Connecticut; and ${ }^{7}$ Barrow Neurological Institute, Phoenix, Arizona

OBJECT Posterior fossa meningiomas represent a common yet challenging clinical entity. They are often associated with neurovascular structures and adjacent to the brainstem. Resection can be undertaken for posterior fossa meningiomas, but residual or recurrent tumor is frequent. Stereotactic radiosurgery (SRS) has been used to treat meningiomas, and this study evaluates the outcome of this approach for those located in the posterior fossa.

METHODS At 7 medical centers participating in the North American Gamma Knife Consortium, 675 patients undergoing SRS for a posterior fossa meningioma were identified, and clinical and radiological data were obtained for these cases. Females outnumbered males at a ratio of 3.8 to 1, and the median patient age was 57.6 years (range 12-89 years). Prior resection was performed in $43.3 \%$ of the patient sample. The mean tumor volume was $6.5 \mathrm{~cm}^{3}$, and a median margin dose of $13.6 \mathrm{~Gy}$ (range 8-40 Gy) was delivered to the tumor.

RESULTS At a mean follow-up of 60.1 months, tumor control was achieved in $91.2 \%$ of cases. Actuarial tumor control was $95 \%, 92 \%$, and $81 \%$ at 3,5 , and 10 years after radiosurgery. Factors predictive of tumor progression included age greater than 65 years (hazard ratio $[\mathrm{HR}] 2.36,95 \% \mathrm{Cl} 1.30-4.29, \mathrm{p}=0.005)$, prior history of radiotherapy (HR 5.19, 95\% $\mathrm{Cl} 1.69-15.94, p=0.004)$, and increasing tumor volume (HR 1.05, 95\% Cl 1.01-1.08, $p=0.005)$. Clinical stability or improvement was achieved in $92.3 \%$ of patients. Increasing tumor volume (odds ratio [OR] 1.06, 95\% $\mathrm{Cl} 1.01-1.10, \mathrm{p}=$ 0.009 ) and clival, petrous, or cerebellopontine angle location as compared with petroclival, tentorial, and foramen magnum location (OR 1.95, 95\% Cl 1.05-3.65, $p=0.036$ ) were predictive of neurological decline after radiosurgery. After radiosurgery, ventriculoperitoneal shunt placement, resection, and radiation therapy were performed in $1.6 \%, 3.6 \%$, and $1.5 \%$, respectively.

CONCLUSIONS Stereotactic radiosurgery affords a high rate of tumor control and neurological preservation for patients with posterior fossa meningiomas. Those with a smaller tumor volume and no prior radiation therapy were more likely to have a favorable response after radiosurgery. Rarely, additional procedures may be required for hydrocephalus or tumor progression.

http://thejns.org/doi/abs/10.3171/2014.10.JNS14139

KEY WORDS stereotactic radiosurgery; Gamma Knife surgery; meningioma; posterior fossa

ABBREVIATIONS $\mathrm{Cl}=$ confidence interval; $\mathrm{CN}=$ cranial nerve; $\mathrm{CPA}=$ cerebellopontine angle; $\mathrm{GKRS}=\mathrm{Gamma} \mathrm{Knife} \mathrm{radiosurgery}$; $\mathrm{HR}=$ hazard ratio; OR = odds ratio; SRS = stereotactic radiosurgery.

SUBMITTED January 18, 2014. ACCEPTED October 8, 2014.

INCLUDE WHEN CITING Published online April 10, 2015; DOI: 10.3171/2014.10.JNS14139.

DISCLOSURE Dr. Lunsford is a consultant and stockholder in AB Elekta. 
$\mathrm{O}$ $\mathrm{F}$ all intracranial meningiomas, approximately $7 \%-12 \%$ are located in the posterior fossa. ${ }^{13,16,56}$ Resection represents the upfront treatment for many patients with symptomatic or progressive posterior fossa meningiomas. ${ }^{50}$ However, the extent of resection can be limited by the meningioma's proximity to critical vascular and neural structures. Gross-total resection rates reported in the literature for posterior fossa meningiomas vary significantly, from $40 \%$ to $96 \%$, and resections are often associated with significant morbidity, mortality, and recurrence. ${ }^{1-5,7,9-12,15-17,20-22,24,27,28,31-33,36,38,41-43,45-48,51,54,56}$ Extent of resection and morbidity rates vary by location of the tumor in the posterior fossa. For instance, in a recent study, morbidity following resection of petroclival meningiomas and cerebellopontine angle (CPA) meningiomas varied from $20.3 \%$ to $47 \%$ and $10.4 \%$ to $35.7 \%$, respectively. ${ }^{14}$ In that same study, extent of complete resection for petroclival meningiomas and CPA meningiomas was $0-48 \%$ and $82 \%-86.1 \%$, respectively. ${ }^{14}$

Some neurosurgeons have recommended radical resection for recurrent meningiomas to prolong life in neurologically stable patients. ${ }^{5}$ Others have advocated for aggressive maximal resection of meningiomas at first presentation with the use of radiosurgery to treat recurrent or residual meningiomas. ${ }^{8,11,26,60}$ Stereotactic radiosurgery (SRS) has become an acceptable treatment option for recurrent/residual meningiomas as well as an upfront option. , $29,30^{2}$

The use of Gamma Knife radiosurgery (GKRS; Elekta $\mathrm{AB}$ ) for intracranial meningiomas had been previously described in the literature. However, there are few large series for which meaningful statistical analysis can be performed. The posterior fossa has unique anatomical concerns in terms of mass effect, and radiosurgical constraints that differ from supratentorial meningiomas. In the current study, we evaluated the outcomes of patients with posterior fossa meningiomas treated with GKRS across a multiinstitutional experience spanning more than two decades.

\section{Methods}

\section{Patient Population}

Seven medical centers participating in the North American Gamma Knife Consortium obtained individual institutional review board approvals to participate in this study. A total of 675 patients were identified with posterior fossa meningiomas managed at least in part by GKRS (Table 1). At each center, retrospective clinical outcome analysis of patients with posterior fossa meningiomas who underwent GKRS was performed. The following centers contributed data for this study: the University of Pittsburgh (271 patients), Yale University (9 patients), Cleveland Clinic (12 patients), University of Sherbrooke (64 patients), Barrow Neurological Institute (118 patients), University of Pennsylvania (44 patients), and the University of Virginia (157 patients).

The records of patients with meningioma who underwent GKRS between 1988 and 2012 were evaluated by clinicians at each center for study inclusion. A database with selected variables was created and sent to all participating centers. Participating centers reviewed the
TABLE 1. Characteristics of 675 patients with posterior fossa meningiomas treated with GKRS

\begin{tabular}{|c|c|}
\hline Characteristic & Total \\
\hline Female sex (\%) & $535(79.3)$ \\
\hline \multicolumn{2}{|l|}{ Age (yrs) } \\
\hline Median & $57.6 \pm 13.4$ \\
\hline Range & $12-89$ \\
\hline Previous resection (\%) & $292(43.3)$ \\
\hline Prior radiotherapy $(\%)$ & $11(1.6)$ \\
\hline \multicolumn{2}{|c|}{ Time from presentation to GKRS (mos) } \\
\hline Mean \pm SD & $28.8 \pm 47.0$ \\
\hline Range & $0-324$ \\
\hline \multicolumn{2}{|l|}{ Initial presentation (\%) } \\
\hline Headache & $227(33.6)$ \\
\hline Subjective dizziness & $236(35.0)$ \\
\hline Subjective cognitive alteration & $41(6.1)$ \\
\hline CN III/IV/VI & $83(13.1)$ \\
\hline CN V & $224(33.3)$ \\
\hline CN VII & $54(8.0)$ \\
\hline CN VIII & $193(28.6)$ \\
\hline CN IX/X & $31(4.6)$ \\
\hline CN XI & $3(2.4)$ \\
\hline CN XII & $16(2.4)$ \\
\hline Cerebellar alteration/deficit & $27(4.0)$ \\
\hline Body weakness & $43(6.4)$ \\
\hline Change in body sensation & $53(7.9)$ \\
\hline \multicolumn{2}{|l|}{ Location (\%) } \\
\hline Clival & $48(7.1)$ \\
\hline Petroclival & $254(37.6)$ \\
\hline Petrous & $33(4.9)$ \\
\hline Tentorial & $145(21.5)$ \\
\hline Cerebellopontine angle & $177(26.2)$ \\
\hline Foramen magnum & $18(2.7)$ \\
\hline \multicolumn{2}{|l|}{ Tumor volume $\left(\mathrm{cm}^{3}\right)$} \\
\hline Mean \pm SD & $6.5 \pm 6.2$ \\
\hline Range & $0.15-41.8$ \\
\hline \multicolumn{2}{|l|}{ Follow-up (mos) } \\
\hline Mean \pm SD & $60.1 \pm 45.4$ \\
\hline Range & $6-252$ \\
\hline
\end{tabular}

medical records of their patients, entered the data in the spreadsheet, and removed all patient identifiers from the database. Pooled and de-identified data were screened by an independent third party for errors. Any uncertainties or ambiguities in the data were addressed to the contributing center. Afterward, data were transmitted to the first author, who along with his coauthors developed this report.

Patients were included in the study if they had a histologically diagnosed WHO Grade I meningioma located within the posterior fossa. In addition, patients were included in this study if they had clinical and neuroimag- 
ing features consistent with a benign meningioma of this neuroanatomical region. Clinical features would include a medical history absent of prior cancer and an intracranial tumor located in the posterior fossa with MRI and/or CT features most consistent with a meningioma. The neuroimaging features included an extraaxial location, contrast enhancement, dural attachment, and for some patients, tumor calcification. For inclusion, patients were required to have a minimum of 6 months of neuroimaging and clinical follow-up after GKRS.

\section{Radiosurgical Technique}

The Gamma Knife Models U, B, C, 4C, or Perfexion were used depending on the technology available at the time of treatment for the participating centers. The radiosurgery began with the application of the Leksell Model $\mathrm{G}$ stereotactic frame (Elekta AB) using local anesthetic supplemented by additional sedation as needed. After stereotactic frame placement, high-resolution stereotactic MRI was performed. In rare cases in which MRI was not feasible or when MRI distortion was a concern, a stereotactic CT scan was obtained. Thin-slice axial and/ or coronal plane images were obtained after intravenous contrast administration. Radiosurgical dose planning was then performed by the neurosurgeon in conjunction with a radiation oncologist and medical physicist.

The mean volume of the posterior fossa meningiomas was $6.5 \mathrm{~cm}^{3}$ (range $0.15-41.8 \mathrm{~cm}^{3}$; Table 1). The median prescription dose delivered to the tumor margin was 13.6 Gy (range 8-40 Gy). The mean prescription isodose line was $48.5 \%$ (range 25\%-65\%; Table 2). Most of the dose plans involved a multiisocentric approach; a mean of 11 isocenters (range 1-59) were used. Dose selection was based on an empirical algorithm that included considerations related to tumor volume, proximity to critical structures such as the brainstem, preexisting neurological deficits, and history of previous treatment with fractionated radiation therapy.

\section{Clinical and Neuroimaging Follow-Up}

Clinical and neuroimaging evaluations were generally performed at follow-up intervals of 6 months for the first 2 years after radiosurgery. In patients who demonstrated no evidence of tumor growth and absence of new neurological findings, follow-up intervals were later increased to every 1-2 years. Whenever feasible, patients underwent follow-up neurological examination and neuroimaging at the respective treating center. However, because participating institutions represent tertiary referral centers, some patients underwent follow-up evaluations by their local physicians. For such patients, clinical notes and actual neuroimaging studies (i.e., not just the radiological reports) were received and reviewed by the treating clinicians who performed the GKRS. The follow-up images were compared with the images obtained at the time of GKRS. Tumor dimensions were assessed in the axial, sagittal, and coronal planes and compared with the comparable measurements on the Gamma Knife neuroimaging studies. Tumor growth, as defined by an increase in 1 of these measurements beyond the tomographic margin of
TABLE 2. Gamma Knife radiosurgery parameters

\begin{tabular}{ccr}
\hline Characteristic & Value \pm SD & Range \\
\hline Median margin dose (Gy) & $13.6 \pm 2.2$ & $8-40$ \\
\hline Mean maximum dose (Gy) & $28.6 \pm 5.6$ & $12-80$ \\
\hline Mean isodose line (\%) & $48.5 \pm 5.3$ & $25-65$ \\
\hline Mean no. of isocenters & $11.0 \pm 7.4$ & $1-59$ \\
\hline
\end{tabular}

uncertainty within the planned treatment volume or adjacent to it, was considered tumor progression.

\section{Statistical Analysis}

Data are presented as median or mean and range for continuous variables, and as frequency and percentage for categorical variables. Calculations of normality were performed by ladder of powers and assessed graphically. Statistical analyses of categorical variables were performed using chi-square, Fisher's exact, and Mantel-Haenszel tests for linear association as appropriate. Statistics of means were conducted using the unpaired Student t-test, both with and without equal variance (Levene's test) as necessary and Wilcoxon rank-sum tests when variables were not normally distributed. The following dependent variables were assessed in univariate and multivariate analysis: tumor-free progression, worsening or new decline in neurological function, and favorable outcome (no tumor progression or worsening or new decline in neurological function). Kaplan-Meier risk of tumor progression was calculated. Factors predictive of tumor progression $(\mathrm{p}<0.15)$ were entered into multivariate Cox regression analyses to assess hazard ratios (HRs). Clinical covariates predicting new or worsening neurological function with a univariate $\mathrm{p}$ value $<0.15$ were included in multivariable logistic regression analyses. Additionally, clinical covariates predicting unfavorable outcome with a univariate $\mathrm{p}$ value $<0.15$ were included in multivariable logistic regression analyses. Clinically significant variables and interaction expansion covariates were further assessed in both Cox and logistic multivariable analyses as deemed relevant. Those $\mathrm{p}$ values $\leq 0.05$ were considered statistically significant.

\section{Results}

\section{Patient and Tumor Attributes}

Of the 675 patients, the median patient age was 57.6 years (range 12-89 years; Table 1). There was a clear sex predilection in the series, with $535(79.3 \%)$ female patients and only 140 (20.7\%) male patients. Two hundred and ninety-two patients $(43.3 \%)$ had previously undergone resection with histologically confirmed WHO Grade I meningiomas. The remaining patients displayed neuroimaging and clinical features consistent with a benign meningioma. Prior fractionated radiation therapy had been used in $1.6 \%$ of patients. The most common presenting symptoms were headaches and dizziness in $33.6 \%$ and $35 \%$ of patients, respectively. Deficits were observed most frequently in cranial nerves (CNs) V (33.3\%) and VIII (28.6\%). 
Meningioma location was classified by the participating centers based upon the location of the majority (i.e., maximum volume) of the tumor. Locations were categorized based upon commonly used neuroanatomical regions of the skull base. . $3,5,27,55,59$ Meningioma locations included $7.1 \%$ clival, $37.6 \%$ petroclival, $4.9 \%$ petrous, $21.5 \%$ tentorial, $26.2 \% \mathrm{CPA}$, and $2.7 \%$ foramen magnum. Mean tumor volume was $6.5 \mathrm{~cm}^{3}$. Mean follow up was 60.1 months (range 6-252 months). Preradiosurgical patient characteristics, presentations, and tumor characteristics are detailed in Table 1.

\section{Radiological Outcome}

The mean follow-up duration was $60.1 \pm 45.4$ months (range 6-252 months). Following radiosurgery, tumor volume decreased by a mean of $1.6 \mathrm{~cm}^{3}$ to a mean posttreatment volume of $4.9 \pm 5.9 \mathrm{~cm}^{3}$ (range $0-33 \mathrm{~cm}^{3}$; Table 3 ). At the last follow-up evaluation, 59 patients $(8.8 \%$ ) had an increase in tumor size, $275(41.0 \%)$ had a decrease in tumor size, and $336(50.2 \%)$ displayed no change in tumor size. Thus, the overall rate of tumor control (i.e., stable or decreased tumor) was $91.2 \%$.

Kaplan-Meier analysis demonstrated radiological progression-free survival at $3,5,10$, and 12 years to be $95 \%$, $92 \%, 81 \%$, and $77 \%$ respectively (Fig. 1). Factors predictive of tumor progression in univariate analysis are displayed in Table 4. Patients with a history of prior resection were not more likely to have tumor progression (HR 1.10, 95\% CI 0.65-1.85, $\mathrm{p}=0.719$; Fig. 2 upper). Progressionfree tumor survival according to mean volume is presented in Fig. 2 lower. There was no statistically significant difference in progression-free survival according to tumor location (Fig. 3).

In Cox multivariate analysis, pre-GKRS covariates predictive of tumor progression included age greater than 65 years (HR 2.36, 95\% CI 1.30-4.29, $\mathrm{p}=0.005$ ), prior history of conventional radiotherapy (HR 5.19, 95\% CI $1.69-15.94, \mathrm{p}=0.004)$, and increasing tumor volume (HR $1.05,95 \%$ CI $1.01-1.08, \mathrm{p}=0.005$; Table 4). There was a trend toward tumor progression with increasing time from symptom onset to GKRS in multivariate analysis (HR $1.01,95 \%$ CI $1.00-1.01, \mathrm{p}=0.065)$. An absence of preGKRS resection was not predictive of tumor progression in multivariate analysis when controlling for other covariates or when assessing for interaction between potential relevant covariates. Patients with tumor progression after radiosurgery were 5.16 times more likely to have new or worsening neurological function (95\% CI 2.58-10.31, p < $0.001)$

\section{Clinical Outcomes}

At last clinical follow-up, 424 patients $(64.9 \%)$ demonstrated no change in clinical outcome, $179(27.4 \%)$ had improvement in clinical outcome, and 50 (7.7\%) had new or worsening neurological function (Table 3). Specific alterations in clinical signs and symptoms following GKRS are detailed in Table 5. Following GKRS, new or worsening $\mathrm{CN}$ dysfunction was observed most commonly in $\mathrm{CN} \mathrm{V}$ followed by aggregate dysfunction of CNs III/IV/ $\mathrm{VI}$ and least commonly in lower cranial nerves including
TABLE 3. Overall clinical and tumor outcomes

\begin{tabular}{lc}
\hline \multicolumn{1}{c}{ Characteristic } & Outcome \\
\hline Pre-GKRS tumor volume $\left(\mathrm{cm}^{3}\right)$ & \\
\hline Mean \pm SD & $6.5 \pm 6.2$ \\
\hline Range & $0.15-41.8$ \\
\hline Post-GKRS tumor volume $\left(\mathrm{cm}^{3}\right)$ & $4.9 \pm 5.9$ \\
\hline Mean \pm SD & $0-33$ \\
\hline Range & \\
\hline Tumor volume (\%) & $336(50.2)$ \\
\hline Decrease & $275(41.0)$ \\
\hline No change & $59(8.8)$ \\
\hline Increase & $424(64.9)$ \\
\hline Clinical outcome (\%) & $179(27.4)$ \\
\hline No change & $50(7.7)$ \\
\hline Improvement & \\
\hline New or worsening neurological function & $557(85.8)$ \\
\hline Overall outcome (\%) & $92(14.2)$ \\
\hline Favorable & $14(2.1)$ \\
\hline Unfavorable & $11(1.7)$ \\
\hline Post-GKRS (\%) & $10(1.5)$ \\
\hline Hydrocephalus & $24(3.6)$ \\
\hline Ventriculoperitoneal shunt placement &
\end{tabular}

CN IX through XII (Table 5). Following radiosurgery, 24 patients $(3.6 \%)$ required resection and $10(1.5 \%)$ underwent radiation therapy to treat tumor progression. Of the 653 patients with reliable clinical follow-up information, 14 patients $(2.1 \%)$ developed hydrocephalus apparent on radiological imaging, and $11(1.7 \%)$ required ventriculoperitoneal shunt placement.

Univariate predictors of new or worsening neurological function after GKRS are displayed in Table 6. These predictors of new or worsening neurological function after GKRS within the univariate analysis were male sex; clival, petrous, and CPA location; prior conventional radiotherapy; symptomatic presentation other than headache; peripheral and maximal dose; and increasing tumor volume (Table 6). In multivariate analysis, increasing tumor volume (OR 1.06, 95\% CI 1.01-1.10, p = 0.009) and clival, petrous, or CPA location versus petroclival, tentorial, and foramen magnum location (OR 1.95, 95\% CI $1.05-3.65, \mathrm{p}=0.036$ ) were predictive of new or worsening neurological function after radiosurgery.

\section{Favorable Outcome After SRS}

A favorable outcome, defined as tumor control along with neurological stability or improvement, was achieved in $557(85.8 \%)$ of 649 patients. An unfavorable outcome (i.e., tumor progression and/or new or worsening neurological function) was found in 92 patients $(14.2 \%)$. Univariate predictors of overall outcome are demonstrated in Table 7. Multivariate predictors of an unfavorable out- 


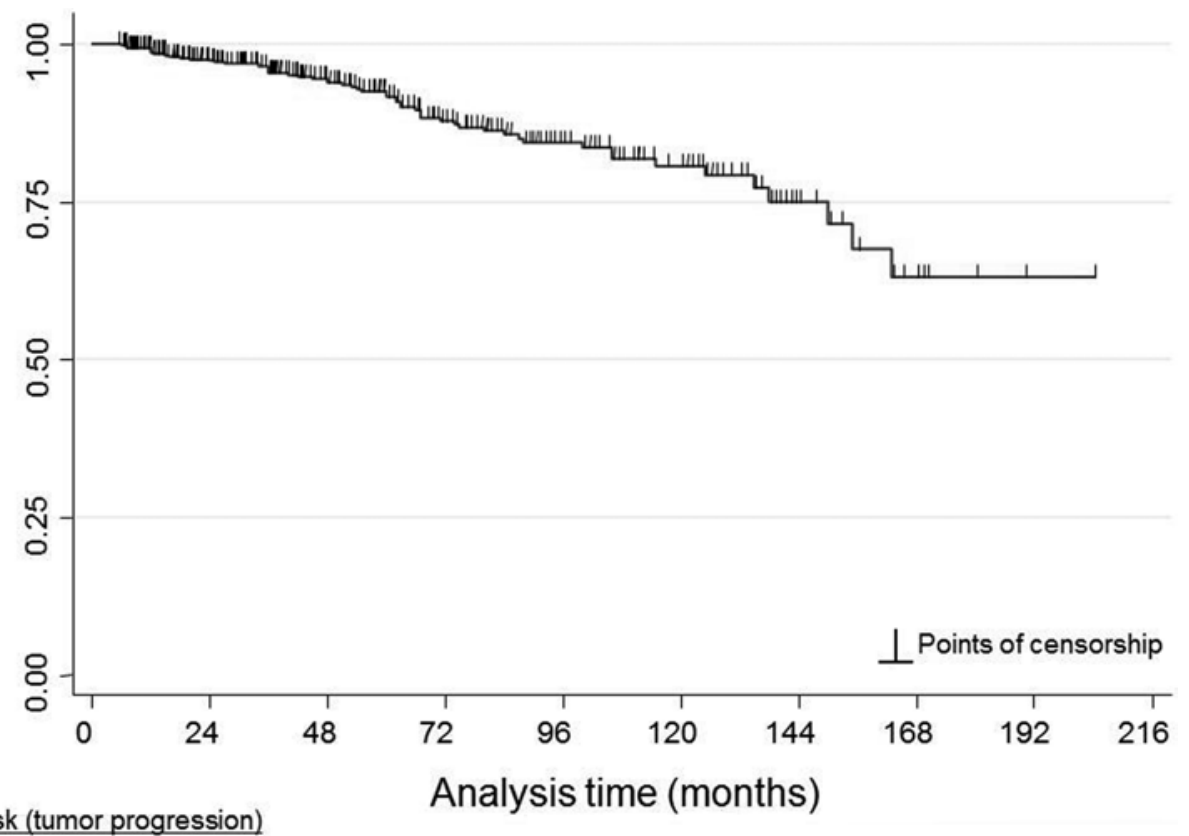

Number at risk (tumor progression)

$675 \quad(28)$

283

102

(7)

21

(3)

1

FIG. 1. Kaplan-Meier plot of progression-free survival after SRS for all 675 patients with posterior fossa meningiomas. Numbers in parentheses represent the number of patients reaching each significant timeline milestone.

come included increasing tumor volume (OR 3.24, 95\% CI $1.12-9.37, \mathrm{p}=0.001)$ and a history of prior conventional radiotherapy (OR 13.46,95\% CI 2.4-75.22, $\mathrm{p}=$ 0.003).

\section{Other Serious Adverse Effects}

In the current study, there was no evidence of radiationinduced tumor formation or malignant transformation of an existing meningioma.

\section{Discussion}

\section{Posterior Fossa Location and Resection}

Meningiomas involving the posterior fossa comprise approximately $7 \%-12 \%$ of all meningiomas..$^{13,16,56}$ Posterior fossa meningiomas present a unique set of challenges as compared with those involving the supratentorial region. Posterior fossa meningiomas are often closely associated with critical arteries, venous sinuses, cranial nerves, and the brainstem, and such proximity to critical structures makes resection more challenging. Also, their resulting growth can lead to mass effect that is less tolerated than their supratentorial counterparts. In instances of appreciable mass effect, hydrocephalus, or significant histological uncertainty, resection remains a valuable approach. Nevertheless, complete resection rates for posterior fossa meningiomas vary substantially, with rates ranging from $40 \%$ to $96 \%$. $^{1-5,7,9-12,15-17,20-22,24,27,28,31-33,36,38,41-}$ $43,45-48,51,54,56$

Although some continue to advocate for aggressive resection, others have instead proposed a more conservative approach involving subtotal resection that is guided by relief of mass effect and preservation of neurological function..$^{6,9,34,60}$ In published series, this contemporary approach has led to morbidity and mortality rates of $0 \%-$ $13 \%$ and $13 \%-40 \%$, respectively. Recurrence rates after an initial resection vary from $12 \%$ to $91 \% .^{1-5,7,9-12,15-17,20-}$ 22,24,27,28,31-33,36,38,41-43,45-48,51,54,56 Such recurrences depend upon the length of follow-up, characteristics of the tumor, and the extent of the initial resection. Although repeat resection is feasible, repeat resection is associated with increased morbidity and mortality due to difficult resection planes. $., 7,22,24,60$

TABLE 4. Factors predictive of tumor progression in univariate and multivariate analyses*

\begin{tabular}{lllr}
\hline Analysis & Pre-GKRS Variables & $\mathrm{HR}(95 \% \mathrm{Cl})$ & $\mathrm{p} \mathrm{Value}$ \\
\hline Univariate & & & \\
\hline & Age $>65$ years & $1.95(1.13-3.34)$ & 0.016 \\
\hline & $\begin{array}{c}\text { Increasing time from } \\
\text { symptom onset }\end{array}$ & $1.01(1.00-1.01)$ & 0.011 \\
& Prior radiotherapy & $6.87(3.22-14.67)$ & $<0.001$ \\
\hline & $\begin{array}{l}\text { Increasing tumor } \\
\text { volume }\end{array}$ & $1.04(1.01-1.08)$ & 0.010 \\
\hline Multivariate & Age $>65$ years & $2.36(1.30-4.29)$ & 0.005 \\
\hline & Increasing tumor & $1.05(1.01-1.08)$ & 0.005 \\
& volume & & 0.004 \\
\hline & Prior radiotherapy & $5.19(1.69-15.94)$ & 0.004 \\
\hline
\end{tabular}

* Factors predictive of tumor recurrence $(p<0.15)$. There was a trend toward increased tumor progression with increasing time from symptom onset in multivariate analysis ( $\mathrm{HR} 1.01,95 \% \mathrm{Cl} 1.00-1.01, \mathrm{p}=0.065)$. 

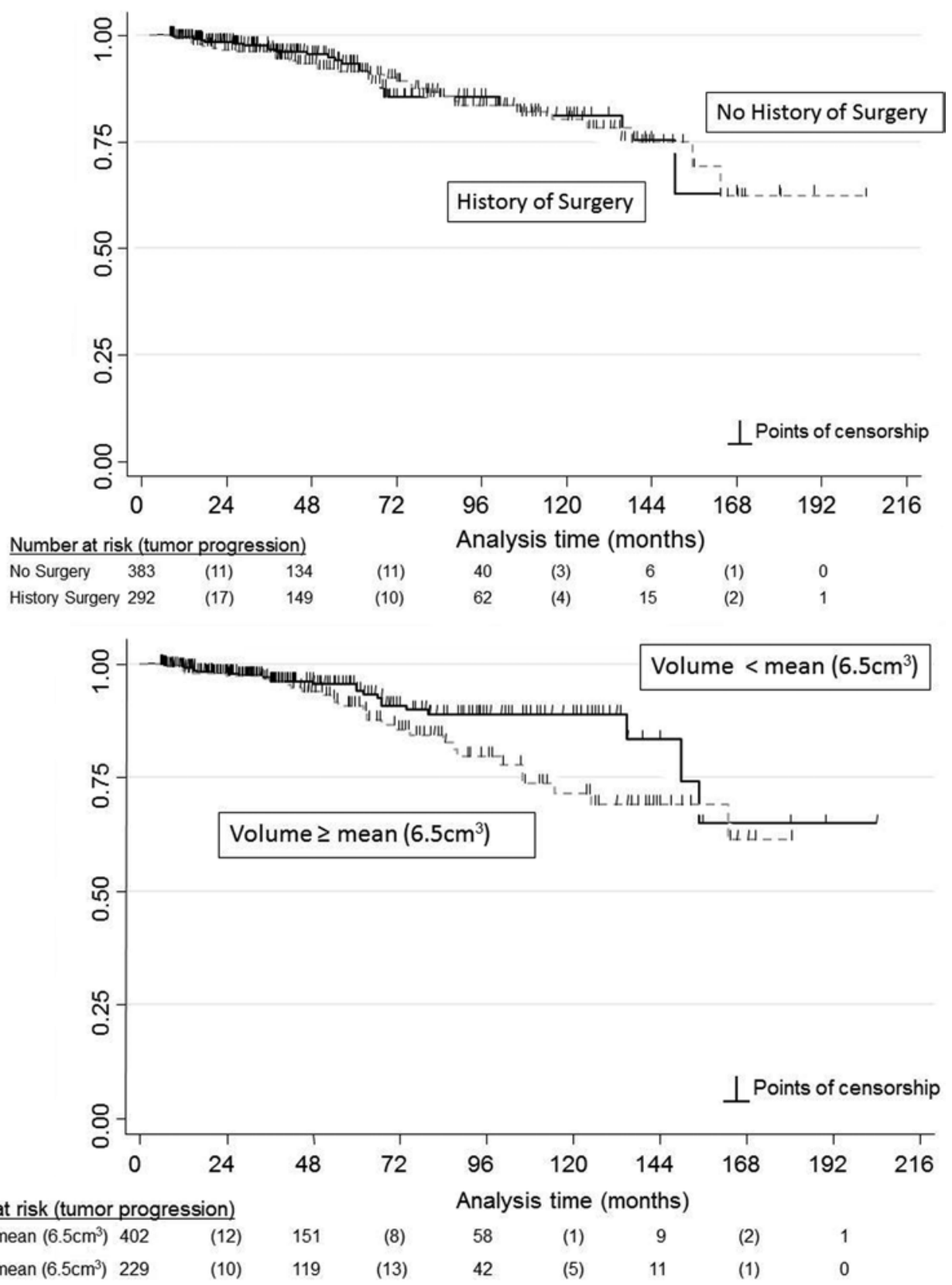

FIG. 2. Kaplan-Meier plot of progression-free survival after SRS for patients with and without a prior resection (upper), and for patients with tumors $<6.5 \mathrm{~cm}^{3}$ versus those with tumors $\geq 6.5 \mathrm{~cm}^{3}$ (lower). Numbers in parentheses represent the number of patients reaching each significant timeline milestone.

\section{Radiation Therapy}

Radiation therapy has been used for some patients with intracranial meningiomas, including ones involving the posterior fossa. Progression-free survival rates at 5 and 10 years after conventional radiotherapy range from $73 \%$ to $92 \%$ and $61 \%$ to $83 \%$, respectively. $23,25,26,35,40,57$ More contemporary techniques such as intensity-modulated radiation therapy and proton therapy offer increased conformality and more sparing of critical structures compared with conventional techniques. ${ }^{44,58}$ The lower integral dose and higher conformality that are touted as the advantages of intensity-modulated radiation therapy and proton beam over conventional radiotherapy techniques for meningiomas have been longstanding features of radiosurgery. While radiotherapy has been used for large volume or poorly delineated posterior fossa meningiomas, its role for smaller to moderately sized and well-demarcated meningiomas involving the posterior fossa has largely been displaced by SRS.

\section{Stereotactic Radiosurgery}

Radiosurgery has proven to be an important tool in the treatment of meningiomas, with most large radiosurgical 


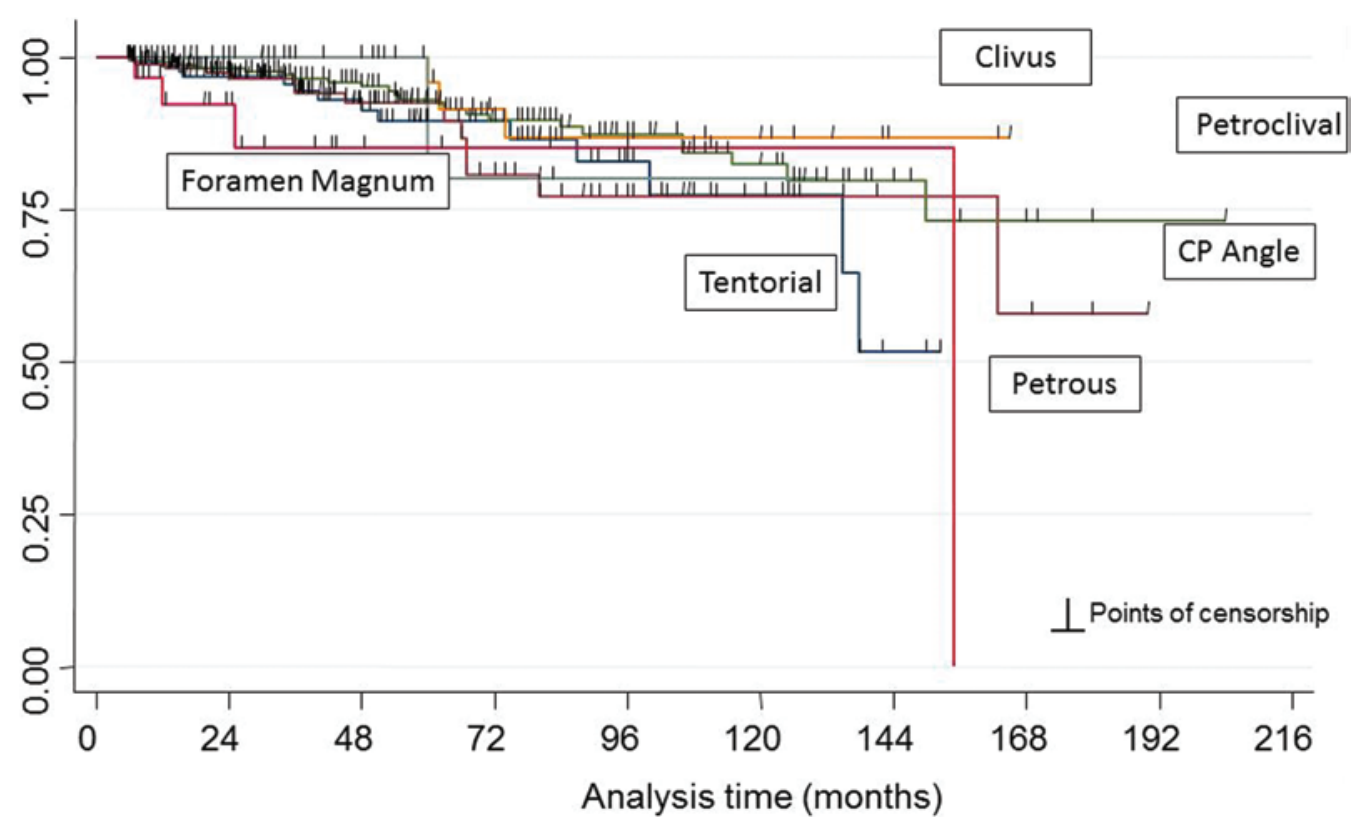

FIG. 3. Kaplan-Meier plot of progression-free survival after SRS for meningiomas in a specific location in the posterior fossa. Figure is available in color online only.

series demonstrating tumor control rates of $85 \%$ or higher for patients with Grade I meningiomas. ${ }^{49}$ Following radiosurgery, tumor control has generally been accompanied by neurological preservation or improvement in the majority of patients. ${ }^{49}$ However, most radiosurgical series have looked broadly at meningiomas of various locations, and few have focused on the challenges associated with meningiomas of the posterior fossa.

In the published literature, there are only a few radiosurgical series that focus exclusively on posterior fossa meningiomas (Table 8). In an earlier series by the University of Pittsburgh team, Subach and colleagues reported on their experience with 62 patients exhibiting petroclival meningiomas. Of these 62 patients, $39(63 \%)$ had at least 1 prior resection. With a median follow-up of 37 months, tumor control was achieved in $92 \%$ of patients, and neurological status improved in $21 \%$ and remained stable in $66 \%$ of patients..$^{55}$ In a later series by that same group, tumor control and neurological preservation were achieved in $90 \%$ and $85 \%$, respectively, of 168 patients with petroclival meningiomas who underwent GKRS. ${ }^{18}$ In another study by the group in Verona, Italy, Nicolato and colleagues ${ }^{39}$ used GKRS to treat 57 patients with 62 posterior fossa meningiomas. With a median follow-up of 28.7 months, tumor regression was observed in $55 \%$ of cases and stability in another $40 \% .{ }^{39}$ Transient side effects due to radiosurgically induced edema were noted in $6.5 \%$, but there were no instances of permanent morbidity associated with GKRS in this series. ${ }^{39}$ More recently from the University of Virginia, a series of 152 patients with posterior fossa meningiomas were evaluated after GKRS. With a median follow-up of 84 months, tumor control and neurological preservation were achieved in $87 \%$ and $91 \%$ of patients, respectively. ${ }^{52}$ Smaller radiosurgical series confirm the efficacy and safety of radiosurgery for patients with posterior fossa meningiomas, even of the foramen magnum. ${ }^{33,61}$

The current series represents the largest one to date for posterior fossa meningiomas treated with radiosurgery (Table 8). This series has sufficient statistical power to permit subgroup analysis to evaluate the effect of tumor location, and the study also gives a broader assessment of neurological complications associated with GKRS. In the current series, tumor control was achieved in $91.2 \%$ of patients at last follow-up. Just if not more importantly, neurological preservation was accomplished in $92.3 \%$ of

TABLE 5. Specific alterations in clinical signs and symptoms following GKRS

\begin{tabular}{lcc}
\hline \multicolumn{1}{c}{ Characteristic } & $\begin{array}{c}\text { Presentation } \\
(\%)\end{array}$ & $\begin{array}{c}\text { New or } \\
\text { Worsening } \\
\text { Function (\%) }\end{array}$ \\
\hline Subjective dizziness & $236(35.0)$ & $34(5.1)$ \\
\hline Subjective cognitive alteration & $41(6.1)$ & $15(2.2)$ \\
\hline CN III/IV/VI & $83(13.1)$ & $21(3.3)$ \\
\hline CN V & $224(33.3)$ & $28(4.2)$ \\
\hline CN VII & $54(8.0)$ & $8(1.2)$ \\
\hline CN VIII & $193(28.6)$ & $12(1.8)$ \\
\hline CN IX/X & $31(4.6)$ & $6(0.9)$ \\
\hline CN XI & $3(2.4)$ & $1(0.2)$ \\
\hline CN XII & $16(2.4)$ & $3(0.5)$ \\
\hline Ataxia & $4(12.4)$ & $14(2.1)$ \\
\hline Other cerebellar alteration/deficit & $27(4.0)$ & $27(4.0)$ \\
\hline Body weakness & $43(6.4)$ & $10(1.5)$ \\
\hline Change body sensation & $53(7.9)$ & $8(1.2)$ \\
\hline
\end{tabular}


TABLE 6. Factors predictive of new or worsening symptoms following radiosurgery in univariate and multivariate analyses*

\begin{tabular}{llll}
\hline \multicolumn{1}{c}{ Analysis } & Pre-GKRS Variables & OR $(95 \% \mathrm{Cl})$ & $\mathrm{p} \mathrm{Value}$ \\
\hline Univariate & & $2.62(0.84-3.09)$ & 0.148 \\
\hline & Male sex & & 0.106 \\
\hline & Location & $1.61(0.90-2.87)$ & 0.017 \\
\hline & Clival, petrous, CPA & 1 & 0.076 \\
\hline Petroclival, tentorium, foramen magnum & $5.43(1.36-21.67)$ & 0.034 \\
\hline & Prior radiotherapy & $2.35(0.92-6.05)$ & 0.147 \\
\hline & Symptomatic presentation other than headache & 0.008 \\
\hline & Increasing peripheral dose & $0.83(0.69-0.99)$ & 0.024 \\
\hline & Increasing maximal dose & $0.95(0.89-1.01)$ & $1.06(1.01-1.10)$ \\
\hline & Isodose volume & $1.05(1.01-1.09)$ & \\
\hline Increasing volume & & 0.036 \\
\hline Multivariate & Location & $1.95(1.05-3.65)$ & 0.009 \\
\hline & Clival, petrous, CPA & 1 & $1.06(1.01-1.10)$ \\
\hline
\end{tabular}

* Factors predictive of tumor recurrence $(p<0.15)$.

patients. Thus, based upon the high chance of tumor control and neurological preservation observed in the current series, those with small to moderately sized posterior fossa meningiomas for whom relief of mass effect is not required would appear well served by GKRS. Those with a smaller tumor volume and no prior radiation therapy were more likely to achieve both tumor control and a favorable neurological outcome after radiosurgery of their posterior fossa meningiomas. The benefit of a smaller tumor volume at the time of radiosurgery does underscore the benefits of a cytoreductive but neurologically preserving surgery

TABLE 7. Factors predictive of an unfavorable outcome in univariate and multivariate analyses*

\begin{tabular}{cccc}
\hline Analysis & \multicolumn{1}{c}{ Variables } & OR $(95 \% \mathrm{Cl})$ & p Value \\
\hline Univariate & & & \\
\hline & $\begin{array}{c}\text { Increasing tumor } \\
\text { volume }\end{array}$ & $1.06(1.02-1.09)$ & 0.001 \\
& $\begin{array}{c}\text { Symptomatic other } \\
\text { than headache }\end{array}$ & $1.79(0.95-3.40)$ & 0.074 \\
& Prior radiotherapy & $26.38(5.50-126.35)$ & $<0.001$ \\
\hline & $\begin{array}{c}\text { Increasing time from } \\
\text { symptom onset }\end{array}$ & $1.01(1.0-1.01)$ & 0.046 \\
\hline & Margin dose & $0.88(0.77-1.00)$ & 0.051 \\
\hline & Isodose line & $0.96(0.92-0.99)$ & 0.013 \\
\hline Multivariate & Increasing tumor & $3.24(1.12-9.37)$ & 0.001 \\
\hline & volume & $13.46(2.4-75.22)$ & 0.003 \\
\hline & Prior radiotherapy
\end{tabular}

* Favorable outcome defined as no tumor progression or new or worsening neurological function. Factors predictive of tumor recurrence $(p<0.15)$. for those patients who have larger tumors at initial presentation. In terms of prior radiotherapy, patients in whom radiation therapy was unsuccessful likely exhibit a more aggressive tumor. Also, prior radiotherapy can require a reduction in the radiosurgical dose below that which might be optimal. Thus, the radiosurgical cohort that had unsuccessful prior radiotherapy is an inherently more challenging one to manage, and the prescription dose lower than what would likely have been given in the absence of prior ionizing radiation makes tumor control less likely.

Cranial nerve dysfunction after GKRS varied depending upon the nerve. Cranial nerve $\mathrm{V}$ and aggregate $\mathrm{CN}$ III, IV, and VI dysfunction were most common whereas lower $\mathrm{CN}$ dysfunction was exceedingly rare (Table 4). The risk factors for $\mathrm{CN}$ palsy after GKRS are likely multifactorial. Variability of the CNs to ionizing radiation may be due in part to the functionality (e.g., special sensory, visceral sensory, visceral motor, and somatic motor), relative radioresistance, vascular supply to the nerve, and irradiated length of a particular nerve. In particular, CN V can routinely tolerate a maximum dose of $80 \mathrm{~Gy}$ in cases of trigeminal neuralgia when such a dose is delivered to a small volume of the nerve. While the doses used in this series to treat meningiomas were substantially lower than $80 \mathrm{~Gy}$, the length of nerve irradiated and the integrated dose to the nerve have been shown to be related to and affect the probability of trigeminal nerve dysfunction after GKRS, and these parameters were likely responsible for some of the CN V dysfunction. ${ }^{34}$ Tumor location (e.g., petrous vs petroclival) also affected the likelihood of new or worsening neurological symptoms following radiosurgery. In cases in which the tumor may have a broader interface with the brainstem or traversing cranial nerves, neurological dysfunction may occur with a higher probability after radiosurgery. 
TABLE 8. Major radiosurgical series for posterior fossa meningiomas

\begin{tabular}{lccccc}
\hline \multicolumn{1}{c}{ Authors \& Year } & $\begin{array}{c}\text { No. of } \\
\text { Patients }\end{array}$ & $\begin{array}{c}\text { Median or Mean } \\
\text { Follow-Up (mos) }\end{array}$ & $\begin{array}{c}\text { Tumor Control } \\
(\%)\end{array}$ & $\begin{array}{c}\text { Neurological } \\
\text { Preservation (\%) }\end{array}$ & $\begin{array}{c}\text { Complications } \\
(\%)\end{array}$ \\
\hline Subach et al., 1998 & 62 & 37 & 92 & 87 & 8 \\
\hline Nicolato et al., 2001 & 57 & 28.7 & 95 & 100 & 6.5 \\
\hline Flannery et al., 2010 & 168 & 72 & 90 & 85 & 8 \\
\hline Starke et al., 2010 & 5 & 60 & 100 & 100 & 0 \\
\hline Starke et al., 2011 & 152 & 84 & 87 & 91 & 9 \\
\hline Zenonos et al., 2012 & 24 & 47 & 100 & 100 & 7.7 \\
\hline Current series & 675 & 60 & 91 & 92.3 & 0 \\
\hline
\end{tabular}

Similarly to patients undergoing resection, radiation therapy, or no treatment, longitudinal follow-up of patients after radiosurgery is required. In the current series, $2.1 \%$ of patients with posterior fossa meningiomas developed hydrocephalus following radiosurgery. The incidence of postradiosurgical hydrocephalus compares favorably with the $16 \%$ incidence noted in a recent surgical series of posterior fossa meningiomas by Nanda et al. ${ }^{37}$ Cerebrospinal fluid malabsorption from a high protein level has been postulated to be the cause of postradiosurgical hydrocephalus. ${ }^{19}$ Such patients require CSF diversion, typically with a shunt as was the case in $1.6 \%$ of patients in the current series. Tumor progression in the current series was rare, but $5.1 \%$ of patients in the current series required additional intervention for their meningioma. Close surveillance with neuroimaging and clinical assessments will allow detection of problems and timely intervention when necessary for radiosurgical patients.

\section{Study Limitations}

The current study represents the largest radiosurgical one to date on this particular indication. Nevertheless, the study has limitations worth noting. The participating centers use a common radiosurgical platform and dose planning software. The outcomes, both favorable and unfavorable, may not be representative of other commercially available systems. Also, radiosurgery comprises a significant portion of the practice of the contributing clinicians in this study. We did not examine the learning curve for this indication nor did we examine the number of cases required to maintain proficiency. In addition, the radiosurgical techniques for planning, treatment, and delivery have evolved over the time span of this study. We do not account for the evolution of the field in assessing outcomes with posterior fossa meningiomas.

The study suffers from inherent biases of a retrospective study. These include selection bias and a lack of a control arm to the study. In particular, selection criteria varied from center to center and as a function of time as the field of radiosurgery has evolved over the past two decades. Also, not all of the tumors were histologically confirmed to be a meningioma. Thus, it is possible that some other benign skull-based lesions were included in this study. However, any patient with histology inconsistent with a WHO Grade I meningioma was excluded from the study. This is true of preradiosurgical histology and histology obtained at the time of resection following failed radiosurgery.

\section{Conclusions}

Gamma Knife radiosurgery affords tumor control and neurological preservation in the vast majority of patients with posterior fossa meningiomas. While resection continues to be of value for relief of mass effect and histological confirmation in ambiguous cases, radiosurgery either as an upfront treatment or an adjuvant one after prior resection represents a valuable neurosurgical tool for treatment of patients with posterior fossa meningiomas.

\section{Acknowledgment}

We appreciate the assistance of Ms. Sharon DeCesare with coordination of data for the North American Gamma Knife Consortium.

\section{References}

1. Adegbite AB, Khan MI, Paine KW, Tan LK: The recurrence of intracranial meningiomas after surgical treatment. J Neurosurg 58:51-56, 1983

2. Al-Mefty O: Clinoidal meningiomas. J Neurosurg 73:840849,1990

3. Al-Mefty O, Fox JL, Smith RR: Petrosal approach for petroclival meningiomas. Neurosurgery 22:510-517, 1988

4. Arnautović KI, Al-Mefty O: Primary meningiomas of the jugular fossa. J Neurosurg 97:12-20, 2002

5. Arnautović KI, Al-Mefty O, Husain M: Ventral foramen magnum meninigiomas. J Neurosurg 92 (1 Suppl):71-80, 2000

6. Asthagiri AR, Helm GA, Sheehan JP: Current concepts in management of meningiomas and schwannomas. Neurol Clin 25:1209-1230, xi, 2007

7. Babu RP, Sekhar LN, Wright DC: Extreme lateral transcondylar approach: technical improvements and lessons learned. J Neurosurg 81:49-59, 1994

8. Barbaro NM, Gutin PH, Wilson CB, Sheline GE, Boldrey EB, Wara WM: Radiation therapy in the treatment of partially resected meningiomas. Neurosurgery 20:525-528, 1987

9. Bassiouni H, Ntoukas V, Asgari S, Sandalcioglu EI, Stolke D, Seifert V: Foramen magnum meningiomas: clinical outcome after microsurgical resection via a posterolateral suboccipital retrocondylar approach. Neurosurgery 59:11771187,2006

10. Bertalanffy H, Gilsbach JM, Mayfrank L, Klein HM, Kawase T, Seeger W: Microsurgical management of ventral and ventrolateral foramen magnum meningiomas. Acta Neurochir Suppl 65:82-85, 1996

11. Black PM, Villavicencio AT, Rhouddou C, Loeffler JS: Aggressive surgery and focal radiation in the management of meningiomas of the skull base: preservation of function 
with maintenance of local control. Acta Neurochir (Wien) 143:555-562, 2001

12. Bruneau M, George B: Foramen magnum meningiomas: detailed surgical approaches and technical aspects at Lariboisière Hospital and review of the literature. Neurosurg Rev 31:19-33, 2008

13. Castellano F, Ruggiero G: Meningiomas of the posterior fossa. Acta Radiol Suppl 104:1-177, 1953

14. Chen CM, Huang AP, Kuo LT, Tu YK: Contemporary surgical outcome for skull base meningiomas. Neurosurg Rev 34:281-296, 2011

15. Cho CW, Al-Mefty O: Combined petrosal approach to petroclival meningiomas. Neurosurgery 51:708-718, 2002

16. Cudlip SA, Wilkins PR, Johnston FG, Moore AJ, Marsh HT, Bell BA: Posterior fossa meningiomas: surgical experience in 52 cases. Acta Neurochir (Wien) 140:1007-1012, 1998

17. Erkmen K, Pravdenkova S, Al-Mefty O: Surgical management of petroclival meningiomas: factors determining the choice of approach. Neurosurg Focus 19(2):E7, 2005

18. Flannery TJ, Kano H, Lunsford LD, Sirin S, Tormenti M, Niranjan A, et al: Long-term control of petroclival meningiomas through radiosurgery. J Neurosurg 112:957-964, 2010

19. Fujimoto A, Matsumura A, Maruno T, Yasuda S, Yamamoto M, Nose T: Normal pressure hydrocephalus after gamma knife radiosurgery for cerebellopontine angle meningioma. J Clin Neurosci 11:785-787, 2004

20. George B, Dematons C, Cophignon J: Lateral approach to the anterior portion of the foramen magnum. Application to surgical removal of 14 benign tumors: technical note. Surg Neurol 29:484-490, 1988

21. George B, Lot G, Boissonnet H: Meningioma of the foramen magnum: a series of 40 cases. Surg Neurol 47:371-379, 1997

22. George B, Lot G, Velut S, Gelbert F, Mourier KL: [French language Society of Neurosurgery. 44th Annual Congress. Brussels, 8-12 June 1993. Tumors of the foramen magnum.] Neurochirurgie 39 (Suppl 1):1-89, 1993 (Fr)

23. Glaholm J, Bloom HJ, Crow JH: The role of radiotherapy in the management of intracranial meningiomas: the Royal Marsden Hospital experience with 186 patients. Int J Radiat Oncol Biol Phys 18:755-761, 1990

24. Goel A, Desai K, Muzumdar D: Surgery on anterior foramen magnum meningiomas using a conventional posterior suboccipital approach: a report on an experience with 17 cases. Neurosurgery 49:102-107, 2001

25. Goldsmith BJ, Larson DA: Conventional radiation therapy for skull base meningiomas. Neurosurg Clin N Am 11:605615,2000

26. Goldsmith BJ, Wara WM, Wilson CB, Larson DA: Postoperative irradiation for subtotally resected meningiomas. A retrospective analysis of 140 patients treated from 1967 to 1990. J Neurosurg 80:195-201, 1994 (Erratum in J Neurosurg 80:777, 1994)

27. Harrison MJ, al-Mefty O: Tentorial meningiomas. Clin Neurosurg 44:451-466, 1997

28. Kandenwein JA, Richter HP, Antoniadis G: Foramen magnum meningiomas-experience with the posterior suboccipital approach. Br J Neurosurg 23:33-39, 2009

29. Kondziolka D, Levy EI, Niranjan A, Flickinger JC, Lunsford LD: Long-term outcomes after meningioma radiosurgery: physician and patient perspectives. J Neurosurg 91:44-50, 1999

30. Kondziolka D, Mathieu D, Lunsford LD, Martin JJ, Madhok R, Niranjan A, et al: Radiosurgery as definitive management of intracranial meningiomas. Neurosurgery 62:53-60, 2008

31. Kratimenos GP, Crockard HA: The far lateral approach for ventrally placed foramen magnum and upper cervical spine tumours. Br J Neurosurg 7:129-140, 1993

32. Levy WJ, Latchaw J, Hahn JF, Sawhny B, Bay J, Dohn DF:
Spinal neurofibromas: a report of 66 cases and a comparison with meningiomas. Neurosurgery 18:331-334, 1986

33. Levy WJ Jr, Bay J, Dohn D: Spinal cord meningioma. J Neurosurg 57:804-812, 1982

34. Massager N, Murata N, Tamura M, Devriendt D, Levivier M, Régis J: Influence of nerve radiation dose in the incidence of trigeminal dysfunction after trigeminal neuralgia radiosurgery. Neurosurgery 60:681-688, 2007

35. Mendenhall WM, Morris CG, Amdur RJ, Foote KD, Friedman WA: Radiotherapy alone or after subtotal resection for benign skull base meningiomas. Cancer 98:1473-1482, 2003

36. Meyer FB, Ebersold MJ, Reese DF: Benign tumors of the foramen magnum. J Neurosurg 61:136-142, 1984

37. Nanda A, Javalkar V, Banerjee AD: Petroclival meningiomas: study on outcomes, complications and recurrence rates. J Neurosurg 114:1268-1277, 2011

38. Nanda A, Vincent DA, Vannemreddy PS, Baskaya MK, Chanda A: Far-lateral approach to intradural lesions of the foramen magnum without resection of the occipital condyle. J Neurosurg 96:302-309, 2002

39. Nicolato A, Foroni R, Pellegrino M, Ferraresi P, Alessandrini $\mathrm{F}$, Gerosa M, et al: Gamma knife radiosurgery in meningiomas of the posterior fossa. Experience with 62 treated lesions. Minim Invasive Neurosurg 44:211-217, 2001

40. Nutting C, Brada M, Brazil L, Sibtain A, Saran F, Westbury $\mathrm{C}$, et al: Radiotherapy in the treatment of benign meningioma of the skull base. J Neurosurg 90:823-827, 1999

41. Pamir MN, Kiliç T, Ozduman K, Türe U: Experience of a single institution treating foramen magnum meningiomas. $\mathbf{J}$ Clin Neurosci 11:863-867, 2004

42. Parlato C, Tessitore E, Schonauer C, Moraci A: Management of benign craniovertebral junction tumors. Acta Neurochir (Wien) 145:31-36, 2003

43. Pirotte B, David P, Noterman J, Brotchi J: Lower clivus and foramen magnum anterolateral meningiomas: surgical strategy. Neurol Res 20:577-584, 1998

44. Pirzkall A, Debus J, Haering P, Rhein B, Grosser KH, Höss $A$, et al: Intensity modulated radiotherapy (IMRT) for recurrent, residual, or untreated skull-base meningiomas: preliminary clinical experience. Int J Radiat Oncol Biol Phys 55:362-372, 2003

45. Roberti F, Sekhar LN, Kalavakonda C, Wright DC: Posterior fossa meningiomas: surgical experience in 161 cases. Surg Neurol 56:8-21, 2001

46. Salas E, Sekhar LN, Ziyal IM, Caputy AJ, Wright DC: Variations of the extreme-lateral craniocervical approach: anatomical study and clinical analysis of 69 patients. J Neurosurg 90 (2 Suppl):206-219, 1999

47. Samii M, Klekamp J, Carvalho G: Surgical results for meningiomas of the craniocervical junction. Neurosurgery 39:1086-1095, 1996

48. Sen CN, Sekhar LN: An extreme lateral approach to intradural lesions of the cervical spine and foramen magnum. Neurosurgery 27:197-204, 1990

49. Sheehan JP, Williams BJ, Yen CP: Stereotactic radiosurgery for WHO grade I meningiomas. J Neurooncol 99:407-416, 2010

50. Simpson D: The recurrence of intracranial meningiomas after surgical treatment. J Neurol Neurosurg Psychiatry 20:22-39, 1957

51. Stafford SL, Perry A, Suman VJ, Meyer FB, Scheithauer BW, Lohse CM, et al: Primarily resected meningiomas: outcome and prognostic factors in 581 Mayo Clinic patients, 1978 through 1988. Mayo Clin Proc 73:936-942, 1998

52. Starke RM, Nguyen JH, Rainey J, Williams BJ, Sherman JH, Savage J, et al: Gamma Knife surgery of meningiomas located in the posterior fossa: factors predictive of outcome and remission. J Neurosurg 114:1399-1409, 2011

53. Starke RM, Nguyen JH, Reames DL, Rainey J, Sheehan JP: 
Gamma knife radiosurgery of meningiomas involving the foramen magnum. J Craniovertebr Junction Spine 1:23-28, 2010

54. Strang RD, al-Mefty O: Small skull base meningiomas. Surgical management. Clin Neurosurg 48:320-339, 2001

55. Subach BR, Lunsford LD, Kondziolka D, Maitz AH, Flickinger JC: Management of petroclival meningiomas by stereotactic radiosurgery. Neurosurgery 42:437-445, 1998

56. Symon L, Pell M, Singh L: Surgical management of posterior cranial fossa meningiomas. Br J Neurosurg 7:599-609, 1993

57. Taylor BW Jr, Marcus RB Jr, Friedman WA, Ballinger WE Jr, Million RR: The meningioma controversy: postoperative radiation therapy. Int J Radiat Oncol Biol Phys 15:299-304, 1988

58. Weber DC, Lomax AJ, Rutz HP, Stadelmann O, Egger E, Timmermann B, et al: Spot-scanning proton radiation therapy for recurrent, residual or untreated intracranial meningiomas. Radiother Oncol 71:251-258, 2004

59. Yaşargil MG: Meningiomas, in: Microneurosurgery: Microneurosurgery of CNS Tumors. Stuttgart: Georg Thieme, 1996, Vol IV B, pp 134-165

60. Zachenhofer I, Wolfsberger S, Aichholzer M, Bertalanffy
A, Roessler K, Kitz K, et al: Gamma-knife radiosurgery for cranial base meningiomas: experience of tumor control, clinical course, and morbidity in a follow-up of more than 8 years. Neurosurgery 58:28-36, 2006

61. Zenonos G, Kondziolka D, Flickinger JC, Gardner P, Lunsford LD: Gamma Knife surgery in the treatment paradigm for foramen magnum meningiomas. J Neurosurg 117:864873,2012

\section{Author Contributions}

Conception and design: Sheehan. Acquisition of data: Kano, Barnett, Mathieu, Chiang, Yu, Hess, McBride, Honea, Nakaji, Lee, Rahmathaulla, Evanoff, Alonso-Basanta, Lunsford. Analysis and interpretation of data: Starke, Lunsford. Drafting the article: Sheehan. Critically revising the article: Sheehan, Starke, Kano, Barnett, Mathieu, Chiang, Yu, McBride, Nakaji, Lee, AlonsoBasanta, Lunsford.

\section{Correspondence}

Jason P. Sheehan, Department of Neurological Surgery, University of Virginia, Charlottesville, VA 22908. email jsheehan@ virginia.edu. 